\title{
A questão terminológica dos organofosforados na Química de Pesticidas: uma abordagem baseada em corpus
}

DOI: http://dx.doi.org/10.21165/el.v48i3.2270

José Victor de Souza'

\section{Resumo}

Neste artigo é discutida a problemática terminológica da Química de Pesticidas, levantando-se a questão da falta de consenso nas traduções, do inglês para o português, de alguns nomes de compostos químicos e de termos técnicos, e como esta questão pode prejudicar a tradução e produção de textos científicos quanto a sua aceitabilidade e naturalidade. A partir dessa premissa, é proposta uma investigação terminológica da área, com a intenção de compreender melhor como funcionam os termos dentro de seu domínio, em ambas as línguas, e identificar possíveis problemas de equivalência. Com a abordagem teórico-metodológica da Linguística de Corpus, termos foram selecionados de um corpus bilíngue de especialidade, criado para esta finalidade, sendo seus significados analisados diante do contexto. Como resultados imediatos, as inconsistências conceituais entre os termos organophosphate e organophosphorus utilizados em inglês e os seus respectivos equivalentes em português foram observadas e estudadas.

Palavras-chave: terminologia; tradução, Química de Pesticidas; organofosforados; organofosfatos.

1 Universidade Estadual Paulista "Júlio de Mesquita Filho" (UNESP), São José do Rio Preto, São Paulo, Brasil; jv.souza3@gmail.com; https://orcid.org/0000-0002-4587-4073 


\title{
The terminological issue of organophosphorus compounds in Pesticide Chemistry: a corpus-based approach
}

\begin{abstract}
This paper aims at discussing a terminological issue in Pesticide Chemistry, pointing out the lack of consensus in the translation of some chemical compound names and of technical terms, from English to Portuguese, and how it may harm the translation and the production of scientific texts, regarding their acceptability and naturalness. From this premise, a terminological investigation of this field is proposed to better understand how these terms work in their scope, in both languages, and to try to identify any problems of equivalence. We used a Corpus-based approach to sort some terms from a comparable bilingual specialized corpus of Chemistry and to analyze the meaning of the terms in their context. As a result, we observed that there are some conceptual inconsistencies between the terms 'organophosphate' and 'organophosphorus', used in English, and their respective equivalents in Portuguese.
\end{abstract}

Keywords: terminology; translation; Pesticide Chemistry; organophosphorus compounds; organophosphate compounds.

\section{Introdução}

Em 2017, o Brasil tornou-se o segundo maior exportador de grãos mundial, movimentando US\$ 1,4 bilhão na economia brasileira. Consequentemente, o país se tornou um dos maiores importadores de pesticidas devido ao aumento da produção de grãos e de etanol. Por esse motivo, pesquisas sobre os efeitos dos agrotóxicos e propostas mais sustentáveis para o seu manejo tornaram-se necessárias. Entretanto, o fato de alguns termos na área da Química de Pesticidas terem se originado no inglês ocasionou certa dificuldade ao buscar-se equivalentes na língua portuguesa. Um exemplo disso é o procedimento High Performance Liquid Chromatography, que apresenta três traduções na língua portuguesa, a saber, "Cromatografia Líquida de Alta \{Pressão/Performance/ Eficiência\}" (PINTO; LIMA, 2018).

Dessa forma, autores de artigos científicos têm utilizado empréstimos, traduções literais ou adaptações que não suprem por completo o significado necessário em português dos termos em inglês. Além disso, alguns nomes de substâncias químicas, cujas diretrizes são de responsabilidade da União Internacional de Química Pura e Aplicada (IUPAC), quando traduzidos para o português por pesquisadores, não seguem uma série de normas e recomendações arbitradas internacionalmente (ABAKERLI et al., 2003).

Essa falta de regularidade ou padronização terminológica prejudica a escrita científica sobre o assunto, pois introduz um fator volátil que impede a ciência de exercer uma de 
suas premissas, que é a reprodutibilidade de métodos. Além disso, comprometem a fluidez e a naturalidade dos textos, aspectos desejados em qualquer produção de texto ou tradução (TAGNIN, 2012).

Este trabalho faz parte de uma pesquisa mais ampla² cujo objetivo é propor uma harmonização terminológica para auxiliar pesquisadores da área em seus relatórios de pesquisas nas duas línguas, e aprimorar a escrita em inglês de alunos do curso de Química. Para tal, é necessária uma investigação terminológica e tradutória da área, para compreender melhor quais são os conceitos atrelados ao seu domínio e como eles se dão em português e em inglês. Para tanto, foi criado um corpus de especialidade comparável bilíngue (português $\leftrightarrow$ inglês) (BERBER SARDINHA, 2000), composto por textos do escopo da Química de Pesticidas divididos em i) um subcorpus composto por artigos científicos escritos em português; ii) um subcorpus composto por abstracts destes artigos em inglês; iii) um subcorpus composto por um livro sobre Química de Pesticidas em inglês, totalizando aproximadamente 406.000 palavras (word tokens). A partir desse corpus, é possível analisar textos autênticos e deles retirar termos para serem comparados.

Assim, descrevemos os processos de compilação de termos através de corpora realizados nessa pesquisa até o momento em que nos deparamos com a questão dos organofosforados, elemento presente com considerável frequência em nosso corpus de especialidade, chegando a um impasse terminológico: a quais conceitos referenciam, respectivamente, os termos organophosphate e organophophorus? Dessa maneira, discorremos sobre os possíveis equivalentes terminológicos desses termos em português e seus significados. Além disso, discutimos questões morfossintáticas a fim de explicar o possível fenômeno de variação conceitual ao constatarmos que somente uma palavra em português é utilizada como equivalente das duas em inglês: organofosforado.

Neste artigo, portanto, procuramos delinear caminhos para que tais problemas possam ser resolvidos perante a realização de um trabalho interdisciplinar entre Tradutores e Químicos, com o intuito de harmonizar os termos traduzidos para a língua portuguesa de forma que atendam às normas da IUPAC e à aceitabilidade por parte de sua comunidade científica.

\section{Fundamentação teórica}

A presente pesquisa envolve conceitos teóricos ligados à Terminologia e à Linguística de Corpus, as quais são relacionadas por Bevilacqua (2013), ao mostrar como a Linguística de Corpus, fundamentada na tradição empirista (BERBER SARDINHA, 2000), pode facilitar o trabalho terminográfico, com ferramentas informatizadas, "desde a

2 "Corpora de textos técnico-científicos utilizados para fins de pesquisa e ensino". Projeto de pesquisa da Profa. Dra. Paula Tavares Pinto. 
própria compilação de corpora, passando pela identificação de candidatos a termos e fraseologias e chegando à identificação de elementos que permitem a elaboração de definição" (BEVILACQUA, 2013, p. 17). Além disso, através da análise dos termos in vivo, ou seja, em seus contextos de uso, identificam-se os termos primeiramente pelos seus significantes e, somente após a análise de seu contexto, é estabelecido seu significado (BEVILACQUA, 2013). A Linguística de Corpus, dessa maneira, ajuda a mostrar os termos mais prováveis e frequentes. Logo, a criação de glossários e dicionários com os termos mais recorrentes, e não com os possíveis, gera maior fluência e naturalidade para os textos produzidos ou traduzidos com o seu auxílio (TAGNIN, 2012). Assim, optamos por montar um corpus para a investigação tradutória e terminológica da área em questão pelo fato de a Linguística de Corpus ser "uma abordagem produtiva dos dados linguísticos" (KRIEGER; SANTIAGO, 2014, p. 50). Por abordagem produtiva, Krieger e Santiago (2014, p. 50) referem-se ao fato de a "Linguística de Corpus [objetivar] a descrição empírica da língua em uso, tomando por base grandes conjuntos de textos autênticos, selecionados e organizados com critérios pertinentes à investigação proposta". Assim, montamos nosso corpus com textos autênticos, ou seja, "aqueles que existem na linguagem e que não foram criados com o propósito de figurarem no corpus" (BERBER SARDINHA, 2000, p. 336), a fim de tentar garantir que os dados coletados representem o que de fato acontece na escrita da área de especialidade.

Ademais, Krieger e Finatto (2004) discutem as relações entre Tradução e Terminologia, ressaltando a naturalidade e, principalmente, a aceitabilidade que um texto possui ao ser produzido, respeitando o uso de termos e das fraseologias pertencentes à área de especialidade. As autoras também enfatizam que, na compilação de termos, uma abordagem qualitativa deve estar presente mesmo quando métodos quantitativos são utilizados como auxílio, como é o caso da geração de listas de frequência, que podem muitas vezes não contemplar termos que, apesar de pouco frequentes, são relevantes para a área de especialidade (KRIEGER; FINATTO, 2004). Sendo assim, não contamos somente com as ferramentas informatizadas para a coleta de unidades terminológicas no corpus. O trabalho com um especialista facilita não somente a coleta de termos como também a própria criação do corpus, ao indicarem-se obras de referência na área.

É importante ressaltar que o estudo de problemas relacionados à tradução de textos técnicos por muito tempo foi negligenciado, como afirmam Krieger e Santiago (2014). Sendo assim, o presente trabalho vem contribuir para que a discussão referente a traduções de textos especializados seja enriquecida:

Isto se deve, em grande parte, à equivocada compreensão de que os textos de natureza técnica, centrados na comunicação das ciências, das técnicas e das tecnologias, não apresentam problemas tradutórios, em razão de sua objetividade e de seu princípio redacional de estarem isentos de ambiguidades. (KRIEGER; SANTIAGO, 2014, p. 43). 
Por fim, este trabalho procura dialogar com as tendências contemporâneas da Terminologia, majoritariamente representadas pela TCT (Teoria Comunicativa da Terminologia). Assim, investigamos a terminologia da Química de Pesticidas a fim de descrever os fenômenos linguísticos que ocorrem nela, e a fim de descobrir quais empecilhos um tradutor pode encontrar ao deparar-se com textos da área. Os fenômenos abordados neste artigo são a variação terminológica, que consiste na coexistência de dois ou mais termos para um mesmo conceito, "resultado da correlação entre fatores linguísticos e sociais bem como da covariação de mudanças associadas ao espaço geográfico e do tempo ou período" (TIMBANE, 2013, p. 152); e a inconsistência terminológica, que ocorre quando ainda não há um consenso na comunidade da área de especialidade quanto a quais conceitos estão atrelados a determinado termo.

Uma postura normativa, portanto, não cabe à nossa pesquisa, uma vez que, assim como o léxico chamado comum, o léxico especializado está sujeito a fenômenos de variação, que não pode ser controlada por dispositivos normativos que tentem exercer uma força centrípeta sobre a língua (BAGNO, 2011). Portanto, é em torno da efetividade comunicativa relacionada ao ofício tradutório em textos especializados que nos focamos.

\section{Metodologia de compilação de termos a partir de corpora}

A coleta de termos da área especializada, como propõem Paiva $(2006,2009)$ e Oliveira e Müller (2013), está sendo feita com a ajuda de um especialista ${ }^{3}$, que foi também quem sugeriu a bibliografia que compõe o corpus. Atualmente, o corpus é composto pelo livro em inglês Pesticide chemistry: crop protection, public health, environmental safety (OHKAWA et al, 2007) e por artigos em português sobre Química de Pesticidas da revista Química Nova. Além disso, há um subcorpus em inglês composto pelos abstracts desses artigos. Todos os textos foram convertidos em formato de documento de texto (.txt) para serem manipulados pelo software AntConc.

Baseado na tipologia de corpus, feita por Berber Sardinha (2000), é possível classificar o corpus compilado como:

- Escrito: composto por textos digitalizados.

- Contemporâneo: são textos atuais.

- Monitor e dinâmico: o corpus cresce ou diminui a fim de refletir o estado atual da língua.

3 Prof. Dr. Marcelo de Freitas Lima, UNESP - Instituto de Biociências, Letras e Ciências Exatas (IBILCE), Departamento de Química e Ciências Ambientais, Laboratório de Química Bio-orgânica Ambiental, LQBoA, São José do Rio Preto, São Paulo, Brasil. 
- Especializado: os textos são todos relacionados ao domínio da Química de Pesticidas.

- Multilíngue: os textos estão em inglês (Pesticide chemistry e abstracts dos artigos) e em português (corpus dos textos dos artigos).

O livro Pesticide chemistry é uma coletânea de artigos que, em suma, trata do estado de arte da Química de Pesticidas, sendo um livro extenso que cobre vários temas na área. Já os artigos da Química Nova partem de uma perspectiva analítica e mais prática, ao apresentarem dados e resultados de relatos de caso, sendo específicos na sua abordagem. Apesar de ambos os subcorpora (do livro e dos textos da revista Química Nova) serem compostos por artigos, eles se dão de maneira diferente em razão do meio em que são veiculados: os artigos da Química Nova estão inseridos em uma revista que traz outros artigos de todas as áreas da Química, não somente a de pesticidas. Além disso, todos os artigos nela possuem um abstract, elemento que não aparece nos artigos do livro Pesticide chemistry que, por sua vez, como se pode intuir pelo nome, só traz artigos que abordam a Química de Pesticidas. Por fim, o nível linguístico é o que mais nos interessa investigar, pois, na presente pesquisa, procuramos identificar e analisar termos e fraseologias da área da Química de Pesticidas, a fim de começar a definir suas características linguísticas.

Após a separação dos textos, foram geradas listas de frequência de palavras no software AntConc, primeiramente, do livro Pesticide chemistry. Após a retirada das stopwords (BEVILACQUA, 2013), que são palavras dispensáveis para a pesquisa, como preposições, artigos etc., permaneceram na lista os substantivos (alguns podem atuar como adjetivos também) relevantes para a pesquisa e mais frequentes. Optamos por dar primazia aos substantivos, pois predefinimos que daríamos atenção primeiramente aos sintagmas nominais. Abaixo, um pequeno recorte da lista, com dez palavras. 
Tabela 1. Dez substantivos filtrados do livro Pesticide chemistry, por frequência.

\begin{tabular}{l|l}
\hline Freq. & Palavra \\
\hline 507 & Pesticide \\
\hline 439 & Activity \\
\hline 401 & Food \\
\hline 301 & Chemical \\
\hline 296 & Resistance \\
\hline 288 & Crop \\
\hline 273 & Pesticides \\
\hline 264 & Data \\
\hline 257 & Crops \\
\hline 247 & Residues \\
\hline
\end{tabular}

Fonte: Elaboração própria.

Depois de observada a palavra pesticide como o substantivo mais frequente do livro, foram gerados clusters também com a ferramenta AntConc. Os clusters mostram quais palavras aparecem próximas à palavra escolhida, podendo-se escolher o número de palavras que compõem o cluster e a frequência mínima com que estes figuram no corpus. Para a coleta de termos neste corpus, os clusters foram limitados ao tamanho de duas palavras, pois clusters maiores, majoritariamente, não formam sintagmas exclusivamente nominais quando requisitados neste caso. Ademais, em razão de este subcorpus ser classificado como de tamanho pequeno-médio (por volta de 159.000 word tokens) (BERBER SARDINHA, 2013), e também devido à possibilidade de haver termos interessantes com baixa frequência no vigente subcorpus, a frequência mínima estipulada foi 1, conforme Krieger e Finatto (2004, p. 205, grifos das autoras) afirmam: "não é porque um dado termo ou expressão ocorram apenas uma única vez em um texto que devem ser a priori descartados de uma 'lista' ou elenco de itens importantes". 


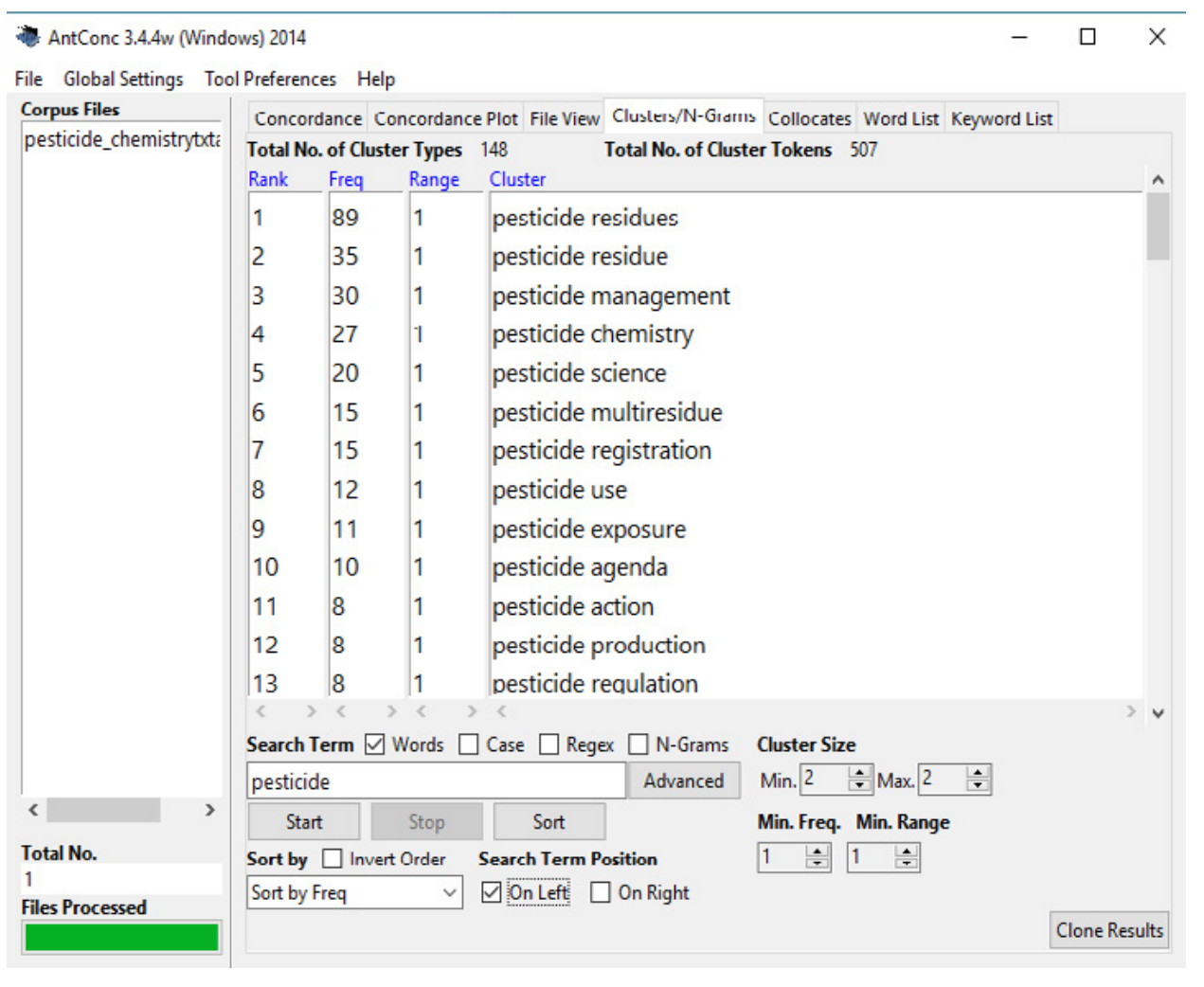

Figura 1. Alguns clusters da palavra pesticide, gerados no AntConc

Fonte: Imagem gerada pelo autor

Todos estes sintagmas acima (Fig. 1) são candidatos a sintagmas terminológicos. 0 processo de criação de clusters repete-se com todos os outros substantivos filtrados para a seleção de mais outros sintagmas.

Para vias de esclarecimento para os procedimentos a seguir, cabe definir o que consideramos um termo nessa pesquisa. De acordo com a TCT (Teoria Comunicativa da Terminologia), termos:

São unidades léxicas (como todo signo linguístico) de um dado código e seu caráter de termo é ativado de acordo com seu uso em um contexto e situação adequados. Essa ativação consiste em uma seleção dos módulos de traços apropriados, que incluem os traços morfossintáticos gerais da unidade e uma série de traços semânticos e pragmáticos específicos que descrevem seu caráter de termo dentro de um determinado domínio. (CABRÉ, 1999, p. 123, tradução de BARROS, 2004 apud PAIVA, 2009). 
Para a busca dos termos equivalentes em língua portuguesa, utilizamos o subcorpus com artigos científicos de química retirados da revista Química Nova. Com seus respectivos abstracts escritos em língua inglesa, realizamos um levantamento de termos em português e seus equivalentes em inglês para uma comparação com os termos levantados a partir do livro Pesticide chemistry. Como exemplo, apresentamos uma lista de frequência, retiradas as stopwords, nas Tabelas 2 e 3. O processo de geração de clusters seguiu os mesmos critérios da compilação, por isso, esse passo será omitido. Apresentamos abaixo a Tabela 2, com os termos em língua portuguesa:

Tabela 2. Dez substantivos, em português, filtrados dos artigos da Química Nova, por frequência

\begin{tabular}{l|l}
\hline Freq. & Palavra \\
\hline 760 & Água \\
\hline 609 & Solo \\
\hline 580 & Amostras \\
\hline 561 & Extração \\
\hline 480 & Agrotóxicos \\
\hline 433 & Compostos \\
\hline 420 & Concentração \\
\hline 420 & Pesticidas \\
\hline 391 & Amostra \\
\hline 371 & Análise \\
\hline
\end{tabular}

Fonte: Elaboração própria.

Conforme podemos observar, todos os termos são relevantes para a área da Química de Pesticida. A seguir, na Tabela 3, apresentamos os termos em inglês os quais já apresentam alguns equivalentes aos da Tabela 2: 
Tabela 3. Dez substantivos filtrados dos abstracts dos artigos da Química Nova, por frequência.

\begin{tabular}{l|l}
\hline Freq. & Palavra \\
\hline 155 & Pesticides \\
\hline 114 & Method \\
\hline 87 & Water \\
\hline 72 & Determination \\
\hline 69 & Pesticide \\
\hline 69 & Samples \\
\hline 59 & Extraction \\
\hline 58 & Soil \\
\hline 50 & Sorption \\
\hline 48 & Compounds \\
\hline
\end{tabular}

Fonte: Elaboração própria.

Como comentado, apesar de inicialmente contarmos com a frequência dos termos, é necessária uma avaliação qualitativa no momento de selecionar quais são os termos candidatos a terminologias da área. Para tal, conforme discutido anteriormente, contamos com a ajuda de um especialista. Os clusters, em português e em inglês, gerados nesse passo foram comparados entre si. Observamos que a palavra pesticide foi a mais frequente em ambos os subcorpora em inglês, ou seja, nos subcorpora do livro e no dos abstracts da revista Química Nova. Dessa maneira, analisamos os clusters em inglês que envolvem a palavra pesticides e também analisamos os seus equivalentes entre os clusters em português. Assim, a seção seguinte é uma descrição de uma questão terminológica com a qual nos deparamos nessa comparação de clusters tendo pesticides como núcleo do sintagma junto a organophosphorus e organophosphate.

\section{Comparação dos termos em inglês e português: organophosphorus, organophosphate e organofosforado}

Coletamos termos nos artigos da revista Química Nova, primeiro dos abstracts em inglês e, em seguida, seus equivalentes em português nos artigos completos. Por fim, checamos se os termos em inglês utilizados por brasileiros seriam os mesmos utilizados no livro Pesticide chemistry, que é uma coletânea de artigos em inglês escritos por pesquisadores internacionais. Na Tabela 4, é possível ver um primeiro exemplo de comparação, recolhido dentre os clusters gerados, sobre o qual discorreremos. 
Tabela 4. Exemplo de termos utilizados por pesquisadores brasileiros na revista Química Nova e termos mais próximos do livro Pesticide chemistry

\begin{tabular}{c|c|c|c}
\hline Autor & $\begin{array}{c}\text { Química Nova } \\
\text { (Português) }\end{array}$ & $\begin{array}{c}\text { Química Nova } \\
\text { (Inglês) }\end{array}$ & $\begin{array}{c}\text { Pesticide } \\
\text { chemistry }\end{array}$ \\
\cline { 1 - 3 } $\begin{array}{c}\text { (LOPES et al., } \\
2011)\end{array}$ & $\begin{array}{c}\text { Pesticidas } \\
\text { organofosforados }\end{array}$ & $\begin{array}{c}\text { Organophosphorus. } \\
\text { pesticides }\end{array}$ & \\
\cline { 1 - 2 } $\begin{array}{c}\text { (GRIZA et al., } \\
\text { 2008) }\end{array}$ & $\begin{array}{c}\text { Agrotóxicos } \\
\text { organofosforados }\end{array}$ & $\begin{array}{c}\text { Organophosphates } \\
\text { pesticides }\end{array}$ & \\
\hline $\begin{array}{c}\text { (OHKAWA et al, } \\
\text { 2007) }\end{array}$ & Organophosphate [and carbate] insecticides & $\begin{array}{c}\text { Organophosphorus } \\
\text { agrochemicals }\end{array}$ \\
& & & \\
\hline
\end{tabular}

Fonte: Elaboração própria.

Apesar de pesticidas e pesticides serem um núcleo comum na maioria dos sintagmas aqui apresentados, o que nos chamou atenção foram os adjuntos: organophosphate, organophosphorus e organofosforado. O primeiro termo apontado, pesticidas organofosforados, foi usado pelos autores do artigo do qual o retiramos como equivalente a organophosphorus pesticides, o que, de acordo com o especialista consultado por nós, atende ao critério convencionado pelos pesquisadores da área como correto. No livro Pesticide chemistry, foi encontrado organophosporus agrochemicals em contexto semelhante, podendo corroborar o termo organophosphorus como equivalente a organofosforado.

Já o segundo termo, agrotóxicos organofosforados, foi utilizado por outros autores como equivalente a organophosphates pesticides. O primeiro problema encontrado foi o fato de o substantivo em inglês (organophosphates), que funciona de maneira parecida com a de um adjetivo ou adjunto adnominal, estar concordando em número com o substantivo a que modifica. Esse tipo de concordância, que ocorre no português, não é válido para o inglês. Desse modo, a fim de realizar a correção gramatical e de facilitar sua citação durante o presente artigo, talvez o termo em inglês seria mais bem empregado como organophosphate pesticides, e assim o empregaremos durante sua descrição e análise. Cabe-nos agora tentar definir quais são as diferenças entre organophosphate e organophosphorus, e verificar se existem mais casos em que ambos são traduzidos como organofosforado. 
Comecemos a descrever como alguns textos em português definem organofosforado. Em um dos artigos do corpus do qual retiramos o termo, podemos encontrar uma definição, a seguir, retirada de Lopes et al. (2011, p. 1279): "compostos organofosforados são compostos orgânicos que contêm um átomo de fósforo em sua estrutura química". Entretanto, ao consultarmos outra fonte, deparamo-nos com uma definição bem mais complexa, a seguir, reproduzida de Baird e Cann (2011, p. 463, grifos dos autores):

Estruturalmente, todas as moléculas de pesticidas organofosforados (OP) podem ser consideradas como derivadas do ácido fosfórico $\mathrm{O}=\mathrm{P}(\mathrm{OH})_{3^{\prime}}$ e consistem em um átomo de fósforo central pentavalente, no qual estão conectados:

- Um átomo de oxigênio ou enxofre ligado ao átomo P por uma ligação dupla;

- Dois grupos metóxi $\left(-\mathrm{OCH}_{3}\right)$ ou etóxi $\left(-\mathrm{OCH}_{2} \mathrm{CH}_{3}\right)$ ligados ao átomo P por uma ligação simples; e

- Um grupo R mais longo e complexo, ligado ao átomo de fósforo por um átomo de oxigênio ou enxofre, o que diferencia um inseticida organofosforado de outro.

Dessa maneira, temos perante nós duas definições que se diferenciam, primeiramente, pelo fato de a primeira trazer uma definição genérica e abrangente, enquanto a outra traz uma definição bem detalhada e específica do que são organofosforados.

Contudo, ao consultarmos a versão original, em inglês, de Baird e Cann (2008), descobrimos que essa definição, na verdade, diz respeito ao composto organophosphate. Ou seja, da mesma maneira como ocorreu em Griza et al. (2008), o termo organofosforado foi utilizado como equivalente de organophosphate. O que nos leva a concluir que Lopes et al. (2011) e Baird e Cann (2011), apesar de usarem o mesmo termo (organofosforado), o utilizam para designar substâncias diferentes. Ao continuarmos a analisar Baird e Cann (2008, p. 445, grifo nosso), encontramos o termo organophosphorus no seguinte contexto: "Malathion is still used in domestic fly sprays and to protect agricultural crops. It and chlorpyrifos were the organophosphorus insecticides commonly detected [...]". Ao consultarmos a versão traduzida, Baird e Cann (2011), atestamos o uso de organofosforado como equivalente de organophosphorus, da mesma maneira como foi visto em Lopes et al. (2011). Vemos então aqui a reincidência da tradução dos termos organophosphate e organophosphorus como organofosforado, na obra de Baird e Cann.

Até esse ponto, atestamos a recorrência do uso de organofosforado para o que aparentam ser dois conceitos diferentes. Entretanto, a própria definição desses conceitos ainda é pouco delineada. Como já apontado, Lopes et al. (2011) definem como organofosforado 
qualquer composto orgânico com fósforo em sua composição. Ao consultarmos Manahan (2000), encontramos os seguintes compostos definidos como organophosphorus compounds:

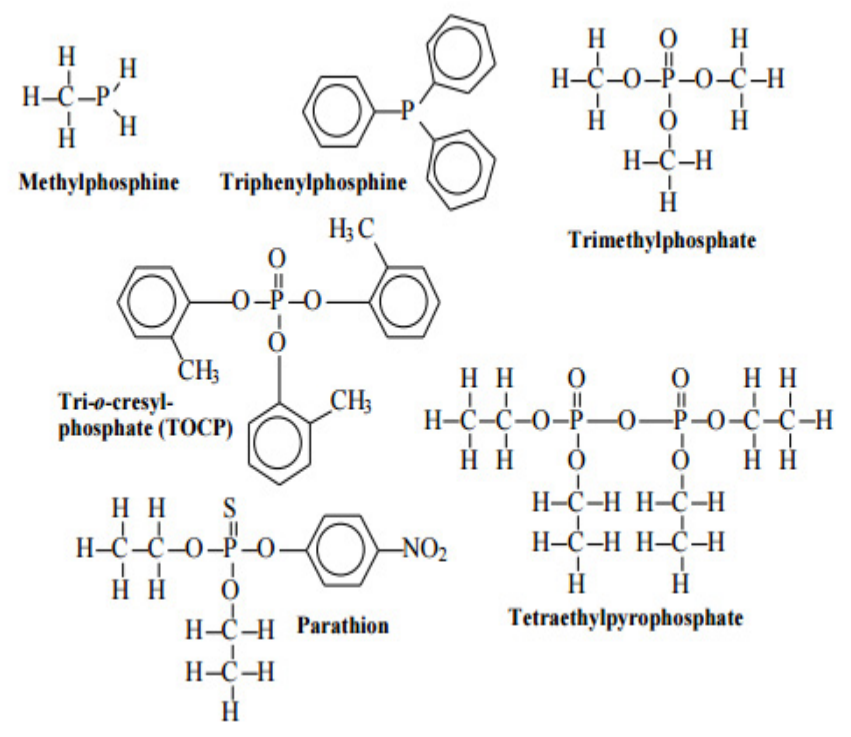

Figura 2. Substâncias consideradas representativas de organophosphorus compounds

Fonte: Manahan (2000)

A descrição de Lopes et al. (2011) para organofosforados parece estar de acordo com os exemplos de Manahan (2000). Podemos, assim, assumir que organophosphorus realmente são qualquer substância orgânica que possua fósforo em sua composição, equivalendo à definição de Lopes et al. (2011) para organofosforados.

Quanto à definição de organophophate, já citamos a definição de Baird e Cann (2008), que, como mostramos, não se refere a organophosphorus, como havíamos pressuposto através da obra traduzida, por ser restrita não só a substâncias orgânicas que possuem o átomo de fósforo em suas estrutura, mas também sejam derivados do ácido fosfórico (com o átomo de fósforo pentavalente), o que resulta na exclusão de substâncias trivalentes como as fosfinas da fig. 2, por exemplo, em que o fósforo liga-se a apenas três ligantes. Assim, acrescentamos aqui exemplos de organophosphate compounds, citados por Manahan (2000), a fim de comparação: 
<smiles>CCCCCCCCCOP(=O)(O)O</smiles><smiles>CCOP(=O)(OCC)OP(=O)(OCC)OCC</smiles>

Tetraethylpyrophosphate
Tri- $\theta$-cresylphosphate, TOCP<smiles>CCCOP(=O)(O)Oc1ccc([N+](=O)[O-])cc1</smiles><smiles>Cc1ccccc1OP(=O)(Oc1ccccc1C)Oc1ccccc1C</smiles><smiles>[R]OP(=S)(O[R])O[Al]CCOP(=S)(OCC)Oc1ccc([N+](=O)[O-])cc1</smiles>

$$
\text { General formula of }
$$

phosphorothionates<smiles>CCOC(=O)CC(SP(=S)(OC)OC)C(=O)OCC</smiles><smiles>[R]OP(=S)(O[R])S[AlH]</smiles>

General formula of phosphorodithioates

Figura 3. Compostos considerados representativos de organophosphate compounds

Fonte: Manahan (2000)

Os exemplos citados por Manahnan (2000) corroboram a definição de Baird e Cann (2008) de maneira bem precisa. Desta maneira, ambas as obras consideram organophosphate esters, phosphorothionate esters e phosphorodithioate esters como organophosphate compounds, como se fosse uma superfamília de substâncias em que o átomo de fósforo central é cercado por quatro ligantes, sendo um deles o grupo fosforila $(P=0)$ ou o grupo fosforotionila $(P=S)$.

Observado isso, podemos afirmar que os organophosphates são uma subcategoria dos organophosphorus, tendo a definição de Baird e Cann (2008) como bem representativa. Entretanto, se voltarmos ao artigo no qual nos deparamos pela primeira vez com o termo organophosphate, o texto de Griza et al. (2008), encontraremos alguns compostos que são chamados de organophosphate pelos autores, mas que não entram na definição de Baird e Cann (2008). Por exemplo, o acefato, na figura abaixo, contrariando o segundo item em destaque de sua definição, ou seja, possuir "Dois grupos metóxi $\left(-\mathrm{OCH}_{3}\right)$ ou etóxi $\left(-\mathrm{OCH}_{2} \mathrm{CH}_{3}\right)$ ligados ao átomo $\mathrm{P}$ por uma ligação simples), e também o terceiro item da mesma definição "Um grupo $\mathrm{R}$ mais longo e complexo, ligado ao átomo de fósforo por um átomo de oxigênio ou enxofre, o que diferencia um inseticida organofosforado de outro.". 


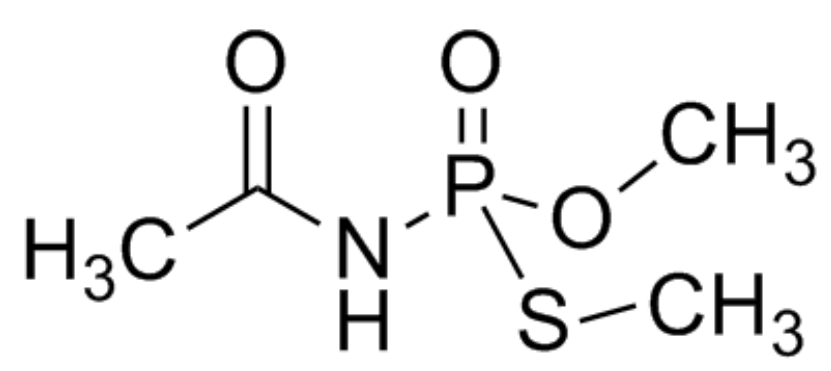

Figura 4. Fórmula estrutural do acefato

Fonte: Imagem gerado pelo autor

Esse composto não entra na definição de Baird e Cann (2008) por conter, como pode ser visto na figura 4, um ligante com enxofre (S) ligado diretamente ao átomo de fósforo e outro mais longo e complexo, mas que está ligado pelo átomo de nitrogênio $(N)$. Como constatado, tal ocorrência não é prevista na descrição de Baird e Cann. Outro exemplo, encontrado em Griza et al. (2008), que não corresponde à definição de Baird e Cann é o metamidafós (fig. 4), caso que envolve novamente um átomo de nitrogênio ligado ao fósforo, mas desta vez não seguido por uma cadeia orgânica. Temos assim, características de organophosphates que não foram contempladas nem pela definição de Baird e Cann (2008) nem pelos exemplos de Manahan (2000).

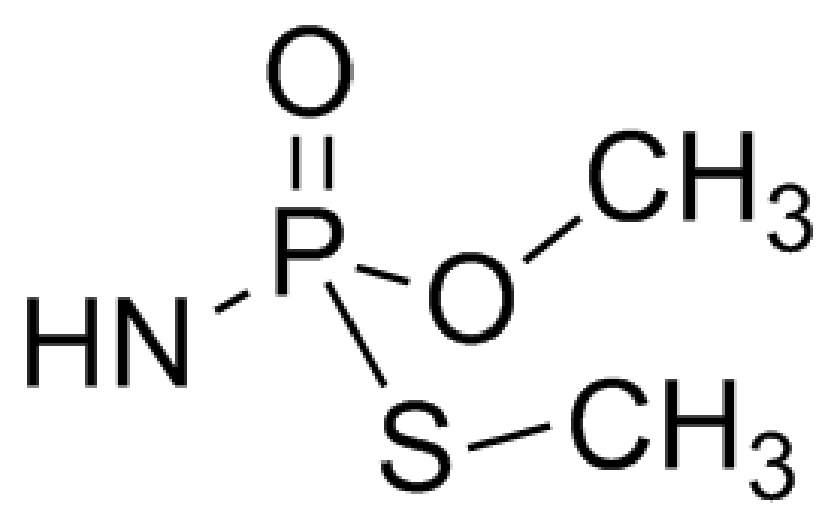

Figura 5. Fórmula estrutural do metamidafós

Fonte: Imagem gerada pelo autor

Além disso, não é difícil encontrar na internet outros exemplos de compostos chamados de organophosphate que não coincidem com as definições e exemplos de Baird e Cann (2008) e Manahan (2000). Dessa maneira, nota-se que as definições e exemplos trazidos pelos autores anteriormente citados não contemplam o real uso do termo por pesquisadores da área. 


\section{Comparação de estrutura linguística: português e inglês}

O trabalho de tradução não envolve apenas a busca por equivalentes léxicos; mais do que isso, é preciso adaptar a estrutura da língua de partida para que ela soe o mais natural possível na língua de chegada. Nos termos analisados em questão, vemos um exemplo de três locuções nominais, sendo os exemplos em inglês formados por dois substantivos (compound noun) e o exemplo em português formado por um substantivo e um adjetivo.

O processo de formação do compound noun é uma característica da estrutura da língua inglesa, na qual um substantivo anteposto a outro assume "ares de adjetivação". Por exemplo: world companies, space administration (LONGO; HÖFLING; SAAD, 1997). Processo semelhante acontece no português, mas nesse caso, o substantivo que assume função semelhante ao de um adjetivo é posposto ao núcleo. Por exemplo: árvore símbolo, artesão artífice (LONGO; HÖFLING; SAAD, 1997). Uma das explicações que Longo, Höfling e Saad (1997) dão para o constante uso de substantivos como adjuntos de outros substantivos na língua inglesa é a baixa produtividade do sufixo formador de adjetivos classificadores predominante na língua (-al).

Já as formações sufixais no português são bem produtivas, o que favorece a adjetivação de substantivos por derivação. Assim, entramos na questão da adjetivação da palavra organofósforo, que seria a tradução literal da palavra organophosphorus. Entretanto, na locução organophosphorus pesticide, é necessário considerar as possibilidades estruturais da língua de chegada ao traduzir. As possibilidades de tradução, considerando a sintaxe da língua portuguesa, poderiam ser:

a) Pesticida organofósforo

b) Pesticida de organofósforo

c) Pesticida organofosfor-[sufixo]

Na possibilidade a) vemos a coordenação de dois substantivos; na b) há uma locução adjetiva modificando o núcleo e na c) há a derivação em um adjetivo, por sufixo, da palavra que funciona como adjunto. A análise quantitativa que a Linguística de Corpus provê nos mostra que a opção c) foi a escolhida pela comunidade da área, com o sufixo -ado sendo o único até então encontrado.

Lembramos que o termo organofosforado vem sendo usado como equivalente a organophosphate e organophoshorus. Isso pode ter acontecido devido à assimilação de conceitos, pois, uma vez que as diferenças entre os dois compostos, em inglês, estão pouco claras, como apresentamos na sessão anterior, podendo somente se afırmar que uma categoria (organophosphate) está contida na outra (organophosphorus), a comunidade brasileira pode ter assimilado, por economia linguística e cognitiva, o mesmo adjetivo (organofosforado) para as duas categorias. 


\section{Considerações finais}

Neste texto, por meio do trabalho com um corpus de tamanho médio, mostramos como o arcabouço teórico-metodológico da Linguística de Corpus pode ser um ponto de partida para a investigação terminológica de áreas especializadas. A comparação dos dados retirados do corpus com materiais de referência recentes da área mostrou-se efetiva na corroboração de nossas hipóteses. Assim, apresentamos um problema específico encontrado na tradução de dois termos da Química de Pesticidas que são influenciados por dois principais aspectos nesse caso: a) o primeiro é o fato de os termos organophosphate e organophosphorus não estarem claros para a comunidade científica da Química quanto a quais conceitos eles ativam em sua área de especialidade; b) o segundo aspecto é a diferença estrutural das línguas portuguesa e inglesa. Dessa maneira, acreditamos que esses fatores condicionaram para o fenômeno aqui constatado: dois termos em inglês se tornaram um em português.

As consequências comunicativas desta questão só podem ser avaliadas pela própria comunidade científica. Aparentemente, o maior problema que pesquisadores brasileiros podem encontrar é optar entre organophosphate ou organophosphorus ao escreverem, por exemplo, um abstract em língua inglesa, uma vez que, na língua portuguesa do Brasil, a forma unificada, organofosforado, parece estar em caminhos de estabelecer-se como a forma mais utilizada em artigos científicos da área.

Atribuímos a inconsistência terminológica da área ao fato de a Química de Pesticidas ser um campo de pesquisa recente. Sendo assim, somente a comunidade científica da área, com o tempo, poderá avaliar quais termos são os mais adequados para determinados contextos. A Química como Ciência possui um histórico de normatização para facilitar a comunicação entre os pesquisadores da área, entretanto, sendo a comunicação especializada passível dos mesmos fenômenos do léxico comum, somente o uso determinará qual forma prevalecerá e qual, eventualmente, desaparecerá.

\section{REFERÊNCIAS}

ABAKERLI, R. B. et al. Regras para nomenclatura dos nomes comuns dos agrotóxicos. Pesticidas. Revista de Ecotoxicologia e Meio Ambiente, v. 13. p. 29-36, jan./dez. 2003.

BAGNO, M. Gramática Pedagógica do Português Brasileiro. São Paulo: Parábola, 2011.

BAIRD, C.; CANN, M. Química Ambiental. Tradução Marco Tadeu Grassi et al. 4. ed. Porto Alegre: Bookman, 2011.

BAIRD, C.; CANN, M. Environmental Chemistry. 4. ed. Nova Iorque: W. H. Freeman \& Company, 2008. 
BERBER SARDINHA, T. Linguística de Corpus: histórico e problemática. DELTA, São Paulo, v. 16, n. 2, p. 323-367, 2000. Disponível em http://www.scielo.br/scielo.php?script=sci_ arttext\&pid=S0102-44502000000200005\&lng=en\&nrm=is. Acesso em: 18 fev. 2017.

BEVILACQUA, C. Por que e para que a Linguística de Corpus na Terminologia. In: TAGNIN, S. E. O.; BEVILACQUA, C. (org.). Corpora na terminologia. São Paulo: Hub Editorial, 2013. p. 11-27.

GRIZA, F. T. et al. Avaliação da contaminação por organofosforados em águas superficiais no município de Rondinha - Rio Grande do Sul. Quím. Nova, São Paulo, v. 31, n. 7, p. 1631-1635, 2008. Disponível em: http://www.scielo.br/scielo.php?script=sci_ arttext\&pid=S0100-40422008000700006\&lng=en\&nrm=iso. Acesso em: 18 fev. 2017.

KRIEGER, M. G.; FINATTO, M. J. B. Introdução à Terminologia: teoria e prática. São Paulo: Contexto, 2004.

KRIEGER, M. G; SANTIAGO, M. S. Estudos de terminologia para a tradução técnica. Rev. de Letras, n. 33, v. 2, p. 42-52, jul./dez. 2014. Disponível em: http://www.periodicos.ufc.br/ revletras/article/view/20447. Acesso em: 12 fev. 2018.

LONGO, B. N. O.; HÖFLING, C.; SAAD, J. C. Os nomes em função adjetiva não predicativa: contrastes. Alfa, São Paulo, n. 41, p. 91-107, 1997. Disponível em: https://repositorio. unesp.br/bitstream/handle/11449/107753/ISSN1981-5794-1997-41-91-107. pdf? sequence=1\&isAllowed=y. Acesso em: 12 fev. 2018.

LOPES, R. M. et al. Aprendizagem baseada em problemas: uma experiência no ensino de química toxicológica. Quím. Nova, São Paulo, v. 34, n. 7, p. 1275-1280, 2011. Disponível em http://www.scielo.br/scielo.php?script=sci_arttext\&pid=S0100-40422011000700029\&ln $\mathrm{g}=$ en\&nrm=iso. Acesso em: 18 fev. 2017.

MANAHAN, S. E. Environmental Chemistry. Boca Raton: CRC Press LLC, 2000.

OHKAWA, H. et al. (ed.). Pesticide chemistry: crop protection, public health, environmental safety. Weinheim: WILEY-VCH Verlag GmbH \& Co. KGaA, 2007.

OLIVEIRA, L. H. M.; MÜLLER, A. F. A terminologia e a utilização de ferramentas computacionais de análise de corpus. In: TAGNIN, S. E. O.; BEVILACQUA, C. (org.). Corpora na terminologia. São Paulo: Hub Editorial, 2013. p. 47-61. 
PAIVA, P. T. P. Estudo em corpora de traduções e três glossários bilíngues nas subáreas de anestesiologia, cardiologia e ortopedia. 2006. Dissertação (Mestrado em Estudos Linguísticos) - Instituto de Biociências, Letras e Ciências Exatas, Universidade Estadual Paulista, 2006. Disponível em: http://hdl.handle.net/11449/93900. Acesso em: 06 abr. 2017.

PAIVA, P. T. P. Uma investigação de traduções de textos da área médica sob a luz dos estudos da tradução baseados em corpus. 2009. Tese (Doutorado em Estudos Linguísticos) Instituto de Biociências, Letras e Ciências Exatas, Universidade Estadual Paulista, 2009. Disponível em: http://hdl.handle.net/11449/103507. Acesso em: 06 abr. 2017.

PINTO, P. T.; LIMA, M. F. A tradução na área de química orgânica: da adaptação à tradução literal. Estudos linguísticos, São Paulo, v. 47, p. 573-585, 2018. Disponível em: https:// revistas.gel.org.br/estudos-linguisticos/article/view/2050. Acesso em: 22 ago. 2019.

TAGNIN, S. E. O. Fraseologia especializada para tradutores: glossários direcionados pelo corpus. In: ORTIZ, M. L. (org.). Tendências atuais na pesquisa descritiva e aplicada em fraseologia e paremiologia. v. 1. Campinas: Pontes, 2012. p. 333-344.

TIMBANE, A. A. A variação terminológica dos termos de futebol moçambicano. In: MURAKAWA, C. A. A.; NADIN, O. L. (org.). Terminologia: uma ciência interdisciplinar. São Paulo: Cultura Acadêmica, 2013. p. 145-165. 